\title{
Compression Behavior of Fluted-Core Composite Panels
}

\author{
Marc R. Schultz ${ }^{1}$ \\ NASA Langley Research Center, Hampton, VA 23681-2199, USA \\ Leonard Oremont ${ }^{2}$ \\ Lockheed Martin Corporation, Hampton, VA 23681-2199, USA \\ J. Carlos Guzman ${ }^{3}$ and Douglas McCarville ${ }^{4}$ \\ The Boeing Company, Seattle, WA 98124-2207, USA \\ Cheryl A. Rose ${ }^{5}$ and Mark W. Hilburger ${ }^{5}$ \\ NASA Langley Research Center, Hampton, VA 23681-2199, USA
}

\begin{abstract}
In recent years, fiber-reinforced composites have become more accepted for aerospace applications. Specifically, during NASA's recent efforts to develop new launch vehicles, composite materials were considered and baselined for a number of structures. Because of mass and stiffness requirements, sandwich composites are often selected for many applications. However, there are a number of manufacturing and in-service concerns associated with traditional honeycomb-core sandwich composites that in certain instances may be alleviated through the use of other core materials or construction methods. Flutedcore, which consists of integral angled web members with structural radius fillers spaced between laminate face sheets, is one such construction alternative and is considered herein. Two different fluted-core designs were considered: a subscale design and a full-scale design sized for a heavy-lift-launch-vehicle interstage. In particular, axial compression of flutedcore composites was evaluated with experiments and finite-element analyses (FEA); axial compression is the primary loading condition in dry launch-vehicle barrel sections. Detailed finite-element models were developed to represent all components of the fluted-core construction, and geometrically nonlinear analyses were conducted to predict both buckling and material failures. Good agreement was obtained between test data and analyses, for both local buckling and ultimate material failure. Though the local buckling events are not catastrophic, the resulting deformations contribute to material failures. Consequently, an important observation is that the material failure loads and modes would not be captured by either linear analyses or nonlinear smeared-shell analyses. Compression-after-impact (CAI) performance of fluted-core composites was also investigated by experimentally testing samples impacted with $6 \mathrm{ft}$.-lb. impact energies. It was found that such impacts reduced the ultimate load carrying capability by approximately $40 \%$ on the subscale test articles and by less than $20 \%$ on the full-scale test articles. Nondestructive inspection of the damage zones indicated that the detectable damage was limited to no more than one flute on either side of any given impact. More study is needed, but this may indicate that an inherent damagearrest capability of fluted core could provide benefits over traditional sandwich designs in certain weight-critical applications.
\end{abstract}

${ }^{1}$ Aerospace Engineer, Structural Mechanics and Concepts Branch, Mail Stop 190, AIAA Senior Member.

${ }^{2}$ Aeronautical Engineer, NASA Langley Research Center, Mail Stop 460.

${ }^{3}$ Manufacturing Research and Development Engineer, Boeing Research \& Technology, P.O. Box 3707, Mail Stop 4R-05

${ }^{4}$ Manufacturing Research and Development Technical Fellow, Boeing Research \& Technology, P.O. Box 3707, Mail Stop 4R-05

${ }^{5}$ Senior Aerospace Engineer, Structural Mechanics and Concepts Branch, Mail Stop 190, AIAA Senior Member. 


\section{Introduction}

$\mathrm{I}_{\mathrm{i}}^{\mathrm{n}}$ recent years, fiber-reinforced composite structures have become more accepted for many different applications, including aerospace vehicles. When properly applied, composite structures can have many benefits over traditional metallic structures, including lower mass, better fatigue resistance, lower part count, and reduced lifecycle cost. During NASA's recent efforts to develop new launch vehicles, composite materials were considered and baselined for a number of structures. Specifically, several of the primary dry shell components such as intertanks and interstages were baselined as composite (see for example, refs. 1 and 2). Various shell designs and construction methods were considered including several composite sandwich shells. Because they possess a low-density core and a high bending stiffness, sandwich shells can be very structurally efficient for applications where the structure is prone to buckling or requires high bending stiffness. Traditional composite sandwich panels are composed of inner and outer facesheets separated by a core material such as balsa wood, polymeric foam, or honeycomb. These facesheets and core are typically joined with film adhesive in either a co-cure (with green facesheets) or a hot-bond (with pre-cured facesheets) operation. Once joined, the facesheets carry tension and compression loads, and the core keeps the facesheets separated while carrying the through-thickness shear loads. Though structurally efficient, traditional composite sandwich structures can have manufacturing and in-service drawbacks. To address some of these shortcomings, alternative sandwich-type structural concepts are being developed. One such structural concept is manifested in fluted-core composite structures (sandwich-like structures that consist of integral angled web members and structural radius fillers spaced between laminate face sheets, see Fig. 1). Fluted-core and similar designs, such as corrugated-core, are not new and have been explored previously through experiment and analysis. ${ }^{3-9}$ Fluted- and corrugated-core structures have also been proposed and/or used on a limited number of aerospace structures. ${ }^{10-13}$ However, a better understanding of the behavior and failure mechanisms of different fluted-corecomposite designs and construction methods is needed if they are to be incorporated into a wider variety of large weight-critical applications. Different applications will drive different requirements, so perceived benefits and drawbacks for honeycomb-core and fluted-core composites are discussed in section II.

The primary loading condition in dry launch-vehicle cylindrical-shell sections is axial compression. The current paper details an effort to better understand the compression behavior and failure modes of fluted-core composite structures through a combination of experimental testing and detailed finite-element analysis (FEA). Two different fluted-core designs were considered: a subscale cross section and a full-scale cross section representative of a design required for the interstage of a heavy-lift launch vehicle. The current analytical and experimental effort is intended to investigate localized compression failures, as opposed to global failures such as Euler buckling. As such, FEA was used to design the test articles and predict behavior under load. Subsequently, samples representing both crosssections were tested in pristine and impact-damaged states. Impacted test articles were tested to provide preliminary data on the impact damage resistance and tolerance of fluted-core composites.

Perceived advantages and disadvantages of fluted-core composites in comparison with honeycomb-core composites are discussed in section II. The test articles are described in section III, and the finite-element modeling and analysis approach used for the pretest predictions is described in section IV. The pretest predictions and the experimental results, including impacted test articles, are discussed in section V. The paper ends with concluding remarks in section VI.

\section{Honeycomb-Core Composites vs. Fluted-Core Composites}

Honeycomb core is a mature product that can be procured in a wide variety of metallic and nonmetallic material and form combinations (e.g., aluminum flex cell and fiberglass/fiberglass hexagonal cell). Moreover, honeycomb

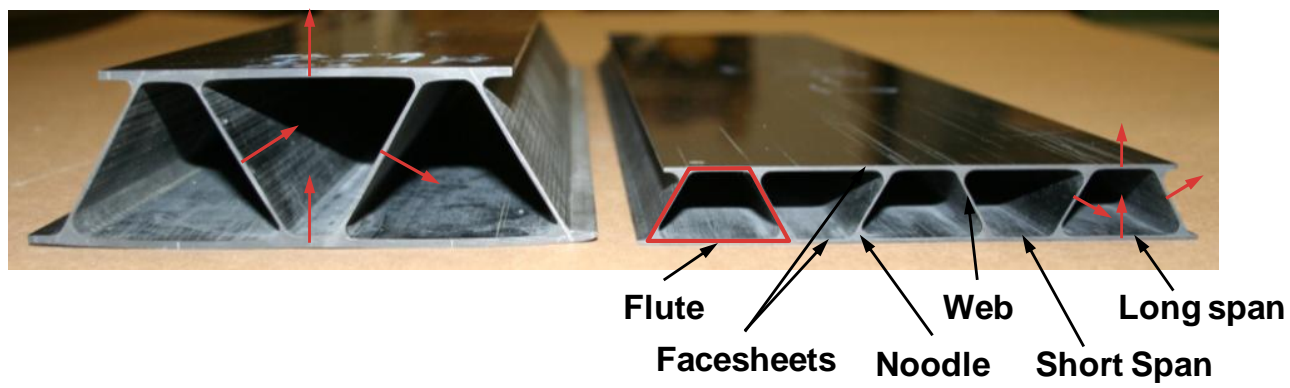

(a) Full scale

(b) Subscale

Figure 1. Cross-sectional geometries of full-scale and subscale specimens, and nomenclature.

2

American Institute of Aeronautics and Astronautics 
core is used to produce sandwich components in numerous industries. For example, honeycomb-core composites are used for engine nacelles in the aerospace industry, for hulls in the marine industry, and for snow boards in the sporting goods industry. Still, honeycomb-core sandwich construction has manufacturing and in-service issues that lead to design knockdown factors. ${ }^{14}$ A number of these issues are listed below.

Manufacturing issues for honeycomb-core composites:

1) It is imperative that the facesheet-to-core bond layer be somewhat elastic and free of porosity, voids, and/or disbonds. However, traditional nondestructive inspection (NDI) methods can not accurately determine the facesheet-to-core bond integrity.

2) Typically, the facesheet-to-core bond layer functions best if filleting between the core cell walls and the facesheets is achieved. This may or may not happen depending on adhesive resin flow and the bag cure environment.

3) Individual core pieces, which are typically limited to roughly $4 \mathrm{ft}$. $\mathrm{x} 8 \mathrm{ft}$., must be $100 \%$ bonded together with foaming or potting adhesives to insure continuous through-thickness shear capability. If any discontinuities in the bond (either core to core or core to facesheet) occur, the overall strength of the panel may be reduced.

4) Co-cured honeycomb-core panels can suffer from facesheet dimpling and/or pillowing if the facesheets are thin, the core cell size is large, or a high bond pressure is used. The resulting fiber waviness can significantly reduce facesheet in-plane properties. In practice, the facesheet-to-honeycomb bond is done at relatively low pressures ( $\leq 45 \mathrm{psi}$ ) to reduce the facesheet dimpling and pillowing. However, curing the facesheets at low pressures under and over the core can result in laminates with higher porosity and hence lower in-plane properties than would be achieved when using standard 85 to 100 psi cure pressures.

5) Low-density core is susceptible to crushing during autoclave bond, especially in ramped areas. This may limit usable bond pressures and require additional bagging features such as edge bars and grip strips.

6) Nonmetallic honeycomb cores are susceptible to moisture absorption prior to bond and in service. If the core is not properly dried prior to bond this moisture can cause a blow out in the core or induce porosity in the film adhesive or facesheets.

7) Honeycomb-core node bonds can break during forming or fatigue loading.

In-service issues for honeycomb-core composites:

1) Aluminum core can galvanically corrode if it is placed in contact with carbon-reinforced composites.

2) Metallic cores can corrode in the presence of trapped moisture.

3) Low-velocity impacts can create facesheet-to-core disbonds that are not readily detectable during visual inspection.

4) Honeycomb-to-facesheet bonds do not have any inherent crack-arrest features.

5) Trapped moisture arising from exposed edges, facesheet punctures, or ingression through thin face sheets can break down core-to-facesheet bonds and core node bonds. This breakdown can be accelerated on aerospace components that are subjected to repeated freeze-thaw cycles.

6) As the core absorbs moisture, the weight and strength of the panel increases and decreases, respectively. Design knockdowns must be used to account for these long-term issues.

Fluted-core structures, especially those fabricated with composite materials, have a more limited history. Various designs (e.g., corrugated web, canted I-beams, and tubes) have been considered and have been made by a variety of manufacturing methods (e.g., co-cure, co-bond, hot bond, and liquid molding). These alternatives have different manufacturing and technology readiness levels (MRL and TRL) and hence different applicability to dry shell structures such as intertanks and interstages. It is believed that the manufacturing methods used to fabricate the test articles discussed herein are low cost and repeatable enough to build extremely large (30-ft.-diameter, 100-ft.-long) high-performance structures. Manufacturing and in-service issues associated with fluted-core composites are listed below. ${ }^{15}$

Manufacturing issues for fluted-core composites:

1) Because of the large variety of designs and manufacturing methods envisioned for fluted-core panels and the relatively small number that have been placed into production, any given design and manufacturing combination may have only limited structural test data associated with it, and may therefore require a lengthy development and certification process. 
2) In order to create continuous load-carrying capability, a large number of fluted-core members must be fabricated and joined with minimal defects; this suggests a high degree of automation and new generation, perhaps costly, equipment and facilities may be required.

3) The facesheets of a fluted-core panel can be inspected using standard pulse echo methods, but the flute walls are harder to see and may require time consuming special inspection methods.

In-service issues for fluted-core composites:

1) There exist limited in-service data for any particular fluted-core design and manufacturing combination. Even for properties that may be considered potentially advantageous (e.g., damage arresting, and moisture/vapor purging capabilities) there may be no in-service data to corroborate estimations.

Since fluted-core composites consist of laminate layers preferentially located at desired angles, they can be cured at high pressures (85-100 psi). These pressures help to minimize porosity and maximize in-plane properties. Unlike honeycomb core, which has directional properties (e.g., the through-thickness shear capability in the transverse direction is typically about half that of the longitudinal, or ribbon direction) that can only be changed in available stepwise density increments, fluted core can be tailored in more ways. Among the fluted-core variables that can be changed to obtain desired properties are the flute height and width, the angle of the web, the web material and layup, the fillet (noodle region) material, and the size of the fillet region.

In summary, there are advantages and disadvantages to both honeycomb-core and fluted-core composites that suggest the use of one or the other in a particular application. Among the advantages of honeycomb core are that it is lightweight, mature, low cost, and there are many varieties available. Some disadvantages of honeycomb-core are that it is vulnerable to moisture, it has low damage tolerance, and the facesheets can have reduced (compared to laminates cured at higher pressures on solid tools) in-plane properties. Advantages of fluted-core over honeycomb core include that it can, in certain instances, be designed to be lighter weight, there are no significant permeability issues, it can have more options for tailoring, and it may have inherent damage containment capability. However, there is much less aerospace experience with fluted core than honeycomb core, and in general fluted core is more costly to fabricate. Still, because of potential fluted-core benefits compared to other sandwich-like structures, it is important to develop a better understanding of its performance under different loading conditions so that fair comparisons and trade studies can be undertaken.

\section{Test Article Description}

The two test-article cross sections considered in this paper are shown in Fig. 1. The subscale test articles were 0.74-in. thick and consisted of five flutes. The full-scale test articles were designed with a cross section representative of that required for a heavy-lift-launch-vehicle interstage, and were 1.6-in. thick and consisted of three flutes. All test articles were fabricated by wrapping unidirectional $350-^{\circ} \mathrm{F}$ toughened carbon-epoxy prepreg plies around trapezoidal mandrels, arranging the wrapped mandrels with pultruded unidirectional-prepreg radius fillers (noodles), and placing prepreg facesheets on top of and below the wrapped mandrels. The entire arrangement was then autoclave co-cured and the mandrels were removed after cure. For the subscale cross section, the total web layup was $[ \pm 45 / \pm 45]_{\mathrm{T}}$ and the total facesheet layup (including the plies originally wrapped around the mandrel) was $[ \pm 45 / 0 / 90]$ s. (Note: The coordinate systems for describing the layouts use 0-degree as the long, axial test-article direction, 90-degree in plane and perpendicular to the 0-degree directions, and normals as shown by the red arrows in Fig. 1.) For the full-scale cross section, the total web layup was $[ \pm 45 / 0 / 90 / 90 / 0 / \pm 45]_{\mathrm{T}}$ and the total facesheet layup (including the plies wrapped around the mandrel) was $\left[ \pm 45 / 0 / 90 / \pm 45 / 0 / 90_{2} / 0 / \mp 45 / 90 / 0 / \mp 45\right]_{\mathrm{T}}$.

Eight test articles are discussed in this paper. Of these, four test articles had the subscale cross section and four had the full-scale cross section. In both of these groups, half were tested in a pristine condition and half were tested after being subjected to a $6 \mathrm{ft}$.-lb. impact from a 1/2-in.-diameter spherical indenter. Each of these test articles had electrical-resistance strain gages applied at locations predicted to experience local buckling. Further, they were painted with a black-and-white speckle pattern to enable full-field optical displacement and strain measurements using the video image correlation system VIC-3D. ${ }^{16}$

The subscale test articles (Fig. 2a) had a total length of 11 in. with 1.5 -in.-long by 0.125 -in.-thick fiberglass tabs applied to both faces at each end. As shown, these tabs had a 45-degree bevel that tapered into the test article. Additionally, $1 \mathrm{in}$. on both ends was potted into a steel frame using epoxy grout. Considering the tabs and potting, the test length of the subscale test articles was 8 in. The subscale test articles were approximately 5.75 -in. wide on the wide face and 5.25-in. wide on the narrow face. The full-scale test articles (Fig. 2b) had a total length of 9.375 in., with 1 in. potted at either end. The full-scale test articles did not have tabs so the test length of the full-scale test 


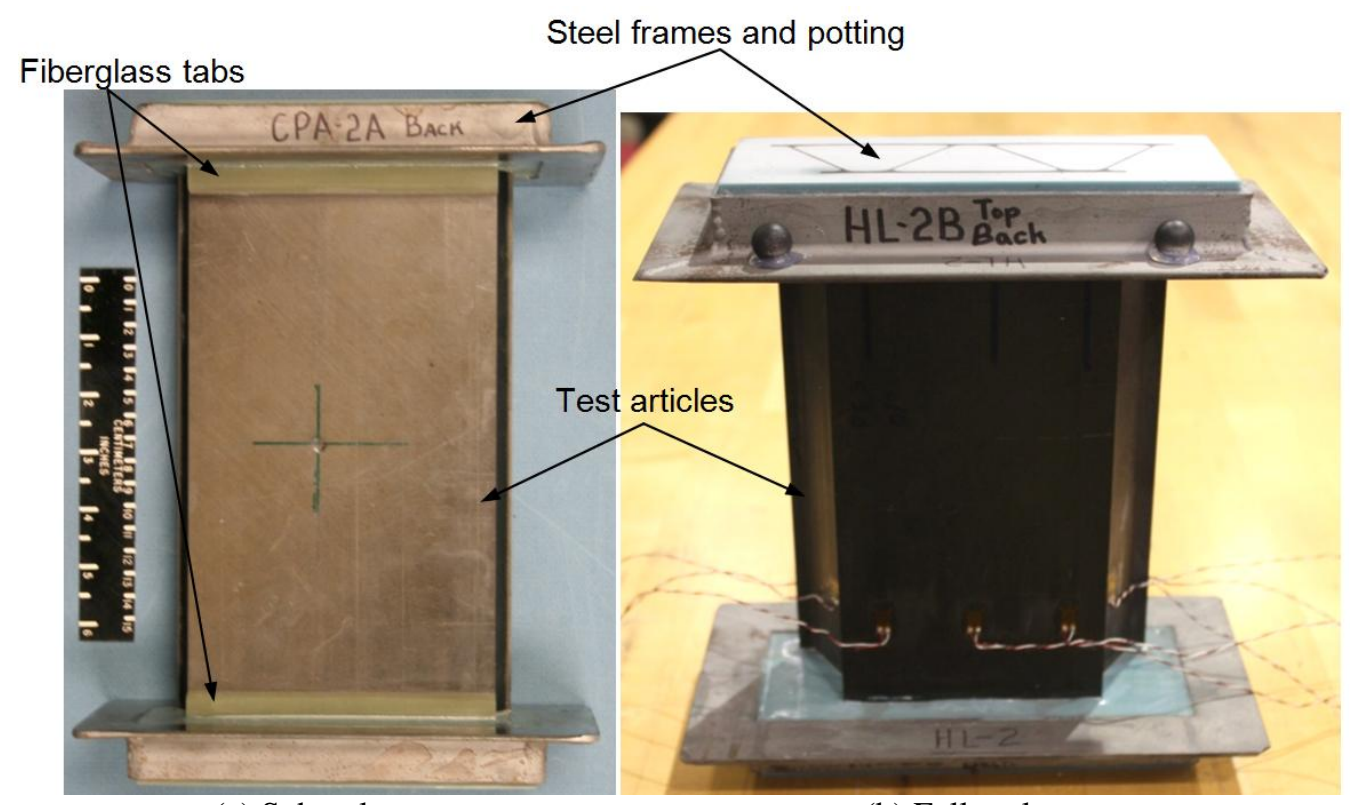

(a) Subscale

(b) Full scale

Figure 2. Test articles.

articles was 7.375 in. The full-scale test articles were 5.50-in. wide on the wide face and 3.875-in. wide on the narrow face. For both the subscale and full-scale test articles, the wide face was termed the front, and the narrow face was termed the back. To prepare the test articles for testing, all edges were machined flat and parallel, or flat and perpendicular.

\section{Finite-Element Modeling and Analysis Approach}

The compression response of fluted-core components has a number of complexities that can make either smeared-shell or linear analyses insufficient for predicting failure. In particular, local buckling can occur in the facesheets and webs before any material failures or global-buckling events. Even if not catastrophic by themselves, these local buckling responses must be captured because they may lead to other failures in the postbuckled range of loading. Smeared-shell analyses are not capable of capturing these local-buckling responses. Geometrically nonlinear analyses that capture enough of the cross-sectional detail are needed to predict the failures that occur in the postbuckled range. Care is required in developing finite-element models that can accurately capture this complex behavior.

The finite-element models used in this study were built using MSC.Patran 2010, ${ }^{17}$ the analyses were performed using Abaqus/Standard 6.9.1, ${ }^{18}$ and the post processing was done using Abaqus/CAE 6.9.1 ${ }^{19}$ In order to account for important details in a computationally efficient manner, and to facilitate ease in post processing, the facesheets, flutes, and noodles were modeled using separate element sets. As shown in Fig. 3, these element sets were combined to create the full finite element model. In the fluted-core test articles discussed herein, each pultruded noodle was surrounded by either the top or the bottom facesheet on the outside, and the flutes on the inside as shown in Fig. 4a. The facesheets and the flutes have a thickness dimension that was much smaller than the other physical dimensions, and were modeled with Abaqus S4R5 shell elements (Figs. 3a and 3b). However, the small noodle dimensions were not very small compared to the cross-sectional dimensions of the fluted-core test articles, so the noodles were modeled with Abaqus C3D6 six-noded, three-dimensional solid wedge elements (Fig. 3c). Fig. 4b shows details of the finite element modeling in the vicinity of a noodle, and is used to describe how the element sets were connected. As can be seen in the figure, the nodal reference surfaces lie along four distinct interfaces regions; 1) the mid-plane of the flute web that is formed by the plies from adjacent flutes, 2) the inner surface of the facesheets adjacent to the flute plies, 3) the outer surface of the noodle adjacent to the flute web plies, and 4) the outer surface of the noodle adjacent to the facesheets. The element sets along each of these interface regions are connected through shared nodes, resulting in coincident shell elements in regions 1 and 2, and shell elements coincident with a solid element face in regions 3 and 4. Offsets were applied to the facesheet and flute element sets to ensure that plies were located 


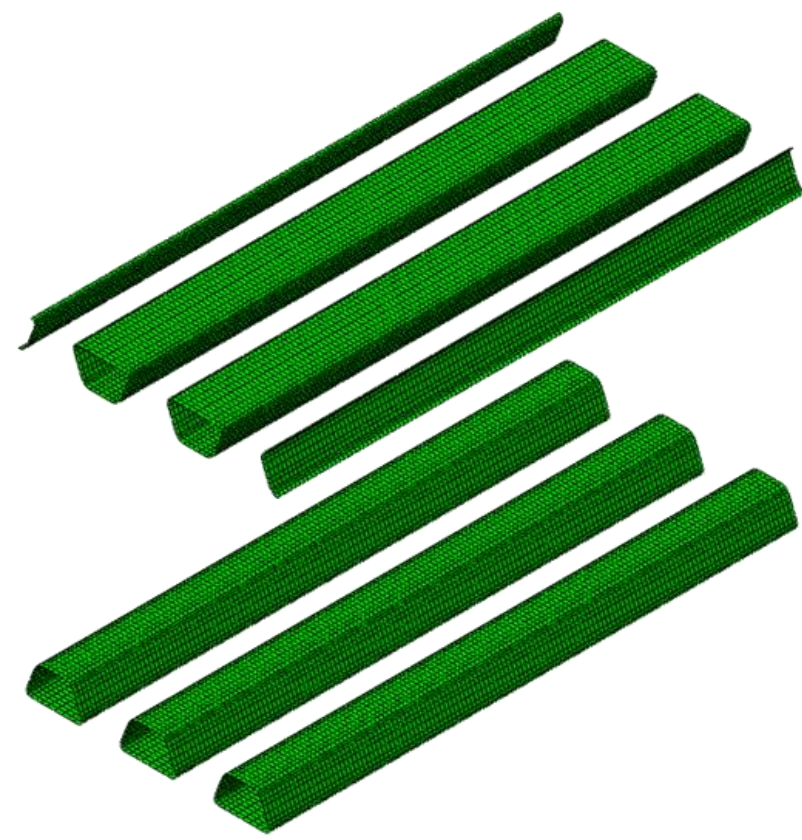

(a) The flutes modeled with shell elements.

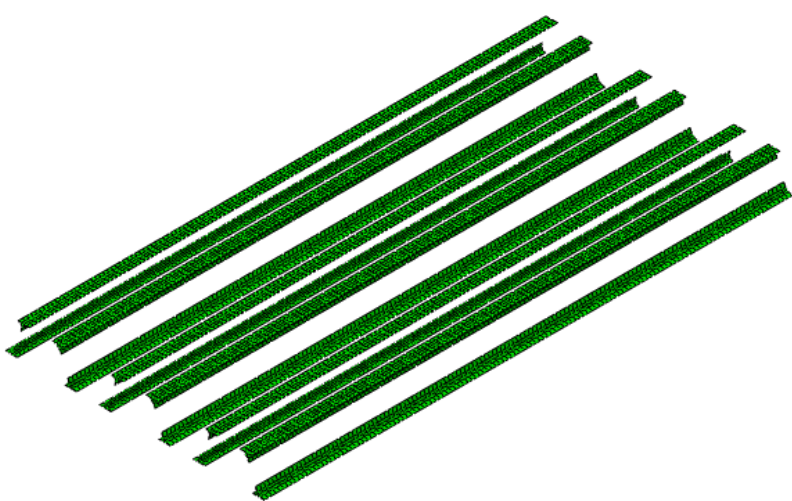

(c) The noodles modeled with 3D solid elements.

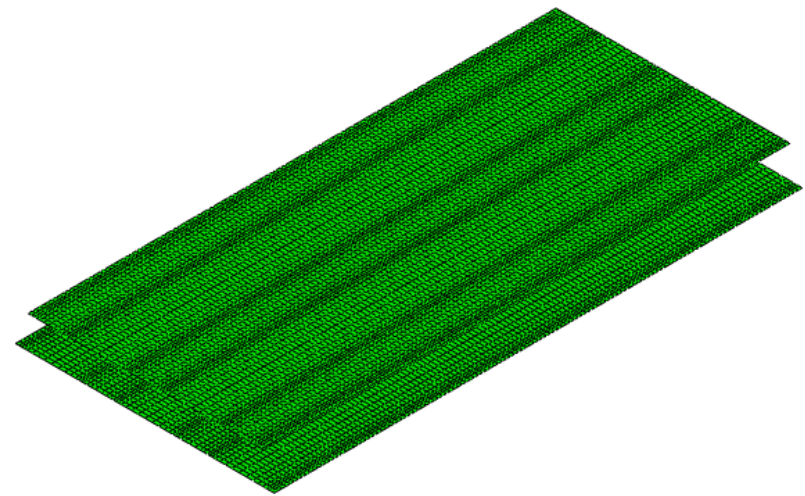

(b) The facesheets modeled with shell elements.

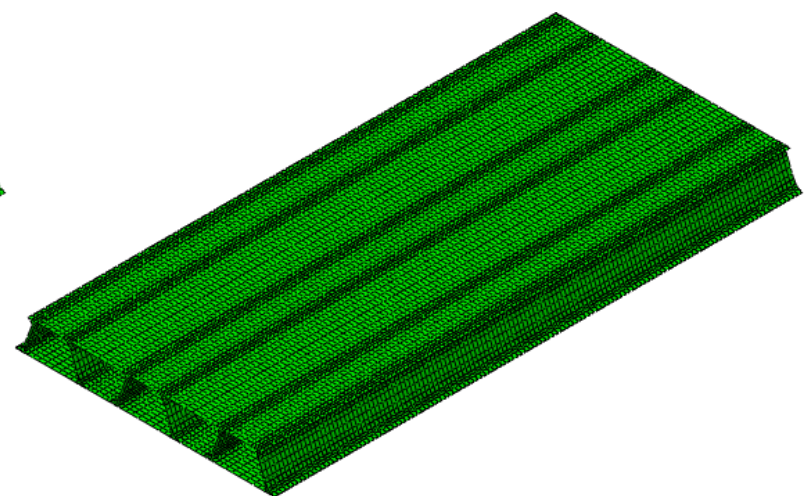

(d) The shell and solid elements combined.

Figure 3. Finite-element model of the subscale test articles showing the separate meshes for the flutes, the facesheets, the noodles, and all meshes combined.

properly with respect to the nodal reference surfaces. Constructing the model in this manner ensured that the stresses and strains in the facesheets, flutes, and noodles could be easily separated during post processing of the results, while at the same time fostering computational efficiency by using the fewest possible nodes.

In order to be able to correctly define the material properties in the individual components, separate coordinate systems were used for each curved and each straight section of the flutes and the noodles. Each flute thus required four cylindrical coordinate systems (one for each corner) and three rectangular coordinate systems for the straight sections. One rectangular coordinate system was shared with the two facesheets and all the noodles, and each web had a rectangular coordinate system that was shared with the adjacent flutes. A full set of material properties was not available for the specific toughened carbon-epoxy used in the construction of the test articles, so linear material properties for the similar material IM7/8552 were used in the modeling of all components. ${ }^{20}$ Compressive material properties were used for the plies expected to be subjected to fiber-direction compression and tensile material properties were used for those plies expected to be subjected to fiber-direction tension.

To be consistent with the test articles, the fiberglass tabs were modeled for the subscale test articles, and the potted ends were modeled for both the subscale and full-scale test articles. Including the potted and tabbed regions enabled the prediction of effective axial stiffness and direct comparison of the axial shortening with the experimental test results. The tabs were modeled using an extra set of elements with appropriate offsets that shared 


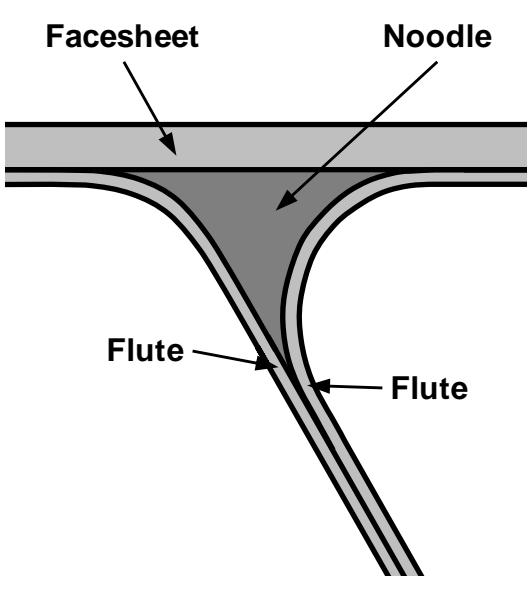

(a) Cross-sectional sketch

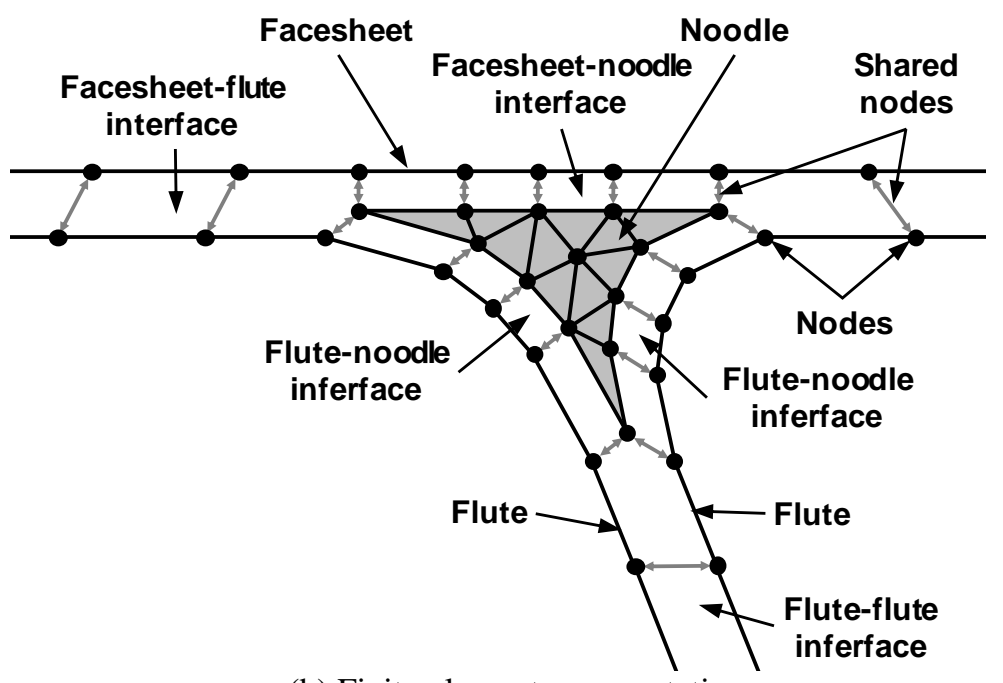

(b) Finite-element representation

(The double-ended arrows indicate shared nodes.)

Figure 4. Details of the noodle region of the finite-element models.

nodes at the interface with the adjacent facesheet elements, therefore adding no additional degrees of freedom The potting constraint was simulated by setting both transverse displacements to zero on all the nodes of elements within the potted region. Except for those nodes at the very ends of the panels, the axial displacements were unconstrained on the nodes in the potted region. To simulate the constraint of the loading platens used in the experiments, the nodes at the very ends of the panels were forced to remain in a plane that was prevented from rotating. Because the modeling approach was slightly refined between models, this was accomplished using different, but essentially equivalent, methods in the subscale and the full-scale models. On each end of the subscale model, the nodes were tied using multiple point constraints (MPCs). These MPCs fixed the dependent nodes to an extra independent node located at the cross-sectional center of each end. On the bottom of the test article, the center node was fixed in all displacements and rotations. On the top, the extra node was fixed in all rotations and in the transverse directions, but was allowed to move in the axial or loading direction. A point force, compressing the article in the axial direction, was then applied to this top center node to simulate the test conditions on the physical test articles. This was the only load applied to the system; the center bottom node provided a reaction force equal in magnitude to the applied load. For the full-scale model, the nodes on the bottom end had boundary conditions that fixed all the degrees of freedom, and nodes on the top end were fixed to a rigid plate. Boundary conditions were used to fix all of the degrees of freedom of the rigid plate except axial translation. An axial point force was applied to the rigid plate to compress the test article. The advantage to this full-scale approach is that contact forces on the panel ends can be output if desired.

Finite-element analyses were conducted to predict the behavior of the pristine test articles under axial compression up to the ultimate failure loads. Geometrically nonlinear static analyses were conducted using the Abaqus built-in modified Riks method, which uses a path-finding algorithm that increases or decreases the applied load to pass through buckling events and evaluate the postbuckled structural response. To allow the Riks method to be successful in its search for a nonlinear solution of the buckling behavior, geometric imperfections based on linear eigenvalue buckling modes were introduced. To obtain the buckling modes for these imperfections, linear eigenvalue buckling analyses were also performed. Using the buckling modes as the imperfection shapes, the nonlinear static Riks analysis was used to predict buckling and material failure events as the axial loads were increased. Material failure was assessed using the maximum-stress failure criterion for fiber-direction, matrixdirection, and shear failures.

\section{Analysis and Experimental Results}

\section{A. Subscale Test Articles}

\section{Pristine Subscale Test Articles}

The finite-element mesh for the pristine subscale test articles is shown in Fig. 3. As was mentioned above, 1.5 in. at each end of the test-article model was considered to have tapered fiberglass tabs bonded to the facesheets, and 1 
in. at each end was considered to be potted. The model had 30,459 nodes, 65,580 elements, and a total of 178,038 degrees of freedom.

Linear eigenvalue analysis predicted local buckling of the facesheets to occur prior to any material failures. Therefore, a geometrically nonlinear analysis was conducted to accurately predict the response of the panels up to ultimate failure. In the nonlinear analysis, a geometric imperfection based on the first linear eigenmode was used so the analysis could capture the local facesheet buckling. The eigenmode imperfection was scaled to produce a small imperfection with a maximum amplitude of 0.005 in. Four failure modes were predicted to occur during loading to ultimate failure (Fig. 5): (a) distributed local facesheet buckling at an average of 37,000 lbs.; (b) nearly simultaneous local in-plane shear failure of the webs and (c) face-sheet fiber failure at 51,000 lbs.; and (d) fiber-direction

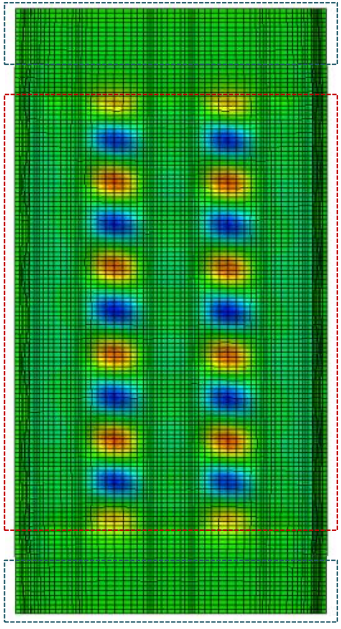

Back

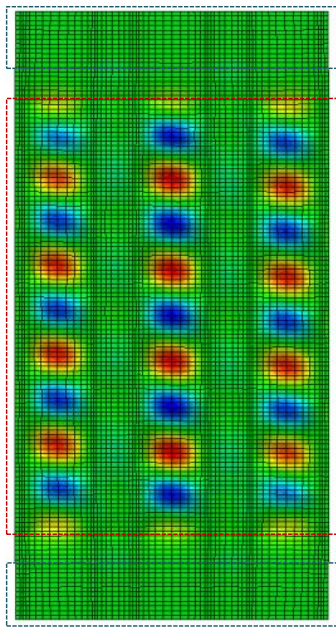

Front

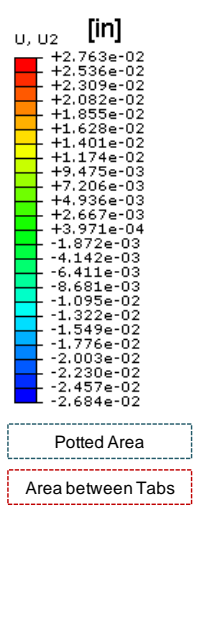

(a) Predicted out-of-plane displacement at 53,100 lbs. applied compressive load.
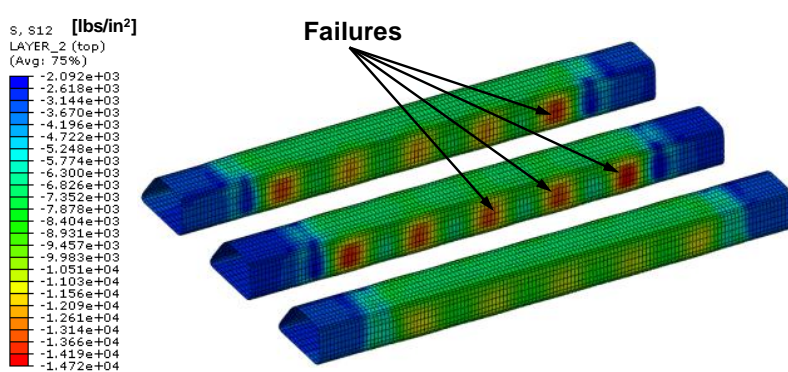

(b) Predicted web shear stresses shown on flutes at 51,400 lbs. applied compressive load

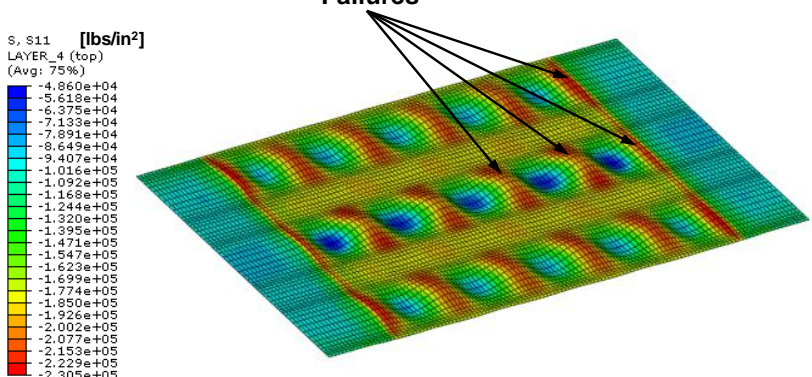

(c) Predicted facesheet fiber-direction stresses for outermost 0 -degree ply of the front face at 51,400 lbs. appled compressive load.

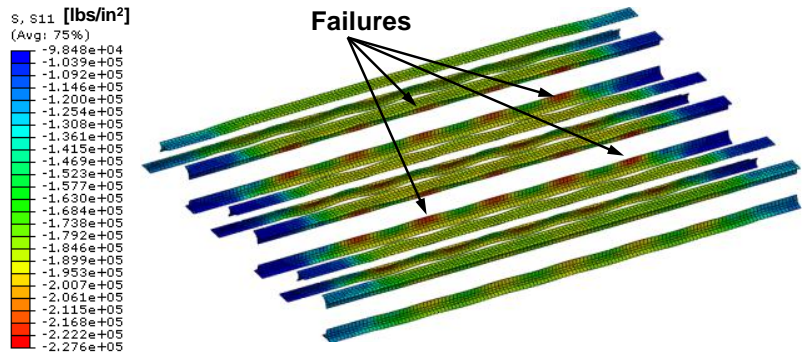

(d) Predicted noodle fiber-direction stresses at 53,000 lbs. appled compressive load.

Figure 5. Predicted subscale failure modes: (a) out-of-plane displacements showing distributed local buckling for a load slightly greater than the predicted failure load; (b) web shear failure shown with shear stress contours; (c) fiber material failure on front shown with fiber-direction normal stress contours, and (d) fiber material failure in noodles shown with fiber-direction normal stress contours. 
compression failure of the noodles at 53,000 lbs. Even though there was no global instability or material damage associated with the onset of local facesheet buckling, it is considered a failure mode because in design there is often no buckling allowed before limit or ultimate load. For both the analysis and test results in this paper, the local buckling in the subscale test articles was defined based on the load and the axial strain from three positions centered on the three long spans of the front-side facesheet and $1.5 \mathrm{in}$. from the top potting. Specifically, the local buckling loads were defined as occurring at the first infinite-slope location in each of these load versus strain curves. These local buckling loads were predicted to be 32,000 lbs., 37,500 lbs., and 41,500 lbs., for an average facesheet buckling load of 37,000 lbs. As shown in Fig. 5a, the fully developed local buckling pattern was predicted to consist of 11 half waves along the length of the long span of each flute. Web shear failure and facesheet fiber failure followed facesheet buckling and were nearly simultaneous events. The web shear failure was distributed along the webs as seen in Fig. 5b. The webs carry very little load so it is unlikely that these failures would cause ultimate failure of the test articles. In contrast, facesheet fiber failure, predicted to occur nearly simultaneously, would likely cause ultimate failure. The facesheet fiber failure was predicted to occur first in concave half waves in the outermost 0-degree plies, as seen in Fig. 5c for the front facesheet. In this prediction, the highest stresses are seen near the tabs. However, all the concave halfwaves have similar predicted stresses and the method of modeling the tabs probably over constrains the test article, which may lead to higher predicted stresses. If the analysis is continued without accounting for material failure, the noodles are predicted to have fiber failure at 53,000 lbs., as shown in Fig. 5d. Because the 0degree facesheet plies and the noodles carry the majority of the compression load, it was predicted that the testarticle ultimate failure would most likely occur at the facesheet fiber failure level, or if not certainly by the noodle fiber failure level. It is important to note that none of these three failure modes would be captured by either linear analyses or nonlinear smeared-shell analyses.

The experimental results for the two pristine subscale test articles (designated CPA-1B and CPA-2B) agreed well with the numerical predictions, as summarized in Table 1 . The initial local buckling loads in CPA-1B and CPA-2B were 37,000 lbs. and 37,500 lbs., respectively. These loads were within the predicted range for buckling loads and within $2 \%$ of the average predicted load of $37,000 \mathrm{lbs}$. There was also reasonably good qualitative agreement between the experiments and the predictions as the buckling pattern developed. For both test articles, the fully developed local buckling mode had 9 half waves along both back-side and all three front-side buckled flutes, which compared well with the prediction of 11 half waves. These buckling patterns are shown in Fig. 6 for test article CPA-2B. After this local buckling, loading was continued until the ultimate load was reached at which point there was a sudden transverse failure across the entire test article width. The location of this failure is shown by the red lines in Fig. 6. The ultimate loads reached experimentally were 51,410 for CPA-1B and 53,500 lbs. for CPA-2B, which were respectively within $1 \%$ and $5 \%$ of the predicted facesheet fiber failure load of 51,000 lbs.

\section{Impacted Subscale Test Articles}

In addition to the pristine test articles, two subscale test articles were impacted with $6 \mathrm{ft}$.-lbs. of energy from a $1 / 2-$ in. spherical indenter. As seen in Fig. 7 and summarized in Table 1, test article CPA-1A was impacted in the center of the test article back side, on one of the short spans between noodles, and test article CPA-2A was impacted just to the left of center on the test article back side, directly over a noodle. The short-span impact caused significant rupturing of the facesheet and a near-complete penetration. This impact was very visible, and as seen in the ultrasonic scan of Fig. 7b, the damage zone was limited by the adjacent noodles but extended within the impacted

Table 1: Analysis and experimental results for pristine and impacted subscale specimens.

$\begin{array}{lccccc} & \begin{array}{c}\text { Analysis } \\ \text { (pristine) }\end{array} & \begin{array}{c}\text { CPA-1B } \\ \text { (pristine) }\end{array} & \begin{array}{c}\text { CPA-2B } \\ \text { (pristine) }\end{array} & \begin{array}{c}\text { CPA-1A } \\ \text { (impacted) }\end{array} & \begin{array}{c}\text { CPA-2A } \\ \text { (impacted) }\end{array} \\ \text { Local facesheet } & 32,000, & 37,000, & 37,500, & \text { N/A } & \text { N/A } \\ \text { buckling loads, lbs. } & 37,500, & 39,500, & 38,000, & & \text { N/A } \\ \text { Half-wave number } & 41,500 & 40,500 & 38,000 & \text { N/A } & 31,700 \\ \text { Ultimate failure load, lbs. } & 11 & 9 & 9 & 30,900 & \text { Noodle } \\ \text { Impact location } & 51,000 & 51,400 & 53,500 & \text { None } & \text { Short span }\end{array}$




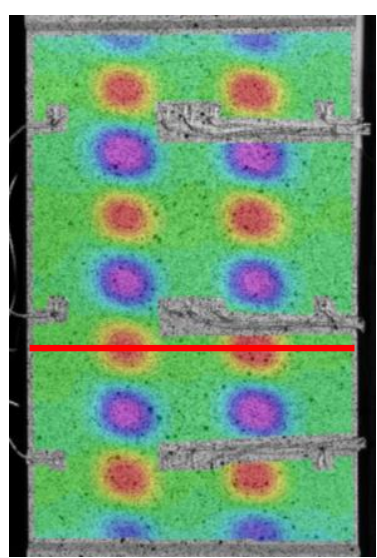

(a) Back

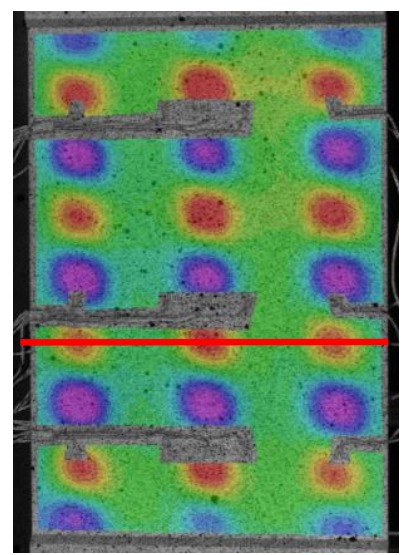

(b) Front

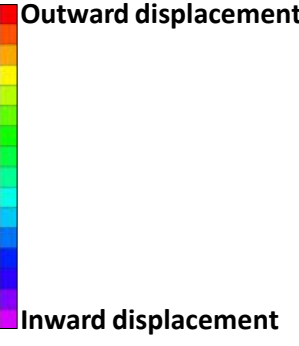

Figure 6. Experimental out-of-plane displacements showing distributed local buckling for CPA-2B at 53,500 lbs. applied compressive load. Red lines indicate locations of compression failure.

short span. The over-noodle impact caused a 0.022-in. dent depth, no visible facesheet rupture, and a damage zone that extended along the noodle (see Fig. 7c). For both impact types, delamination in the faces was clear in the ultrasonic scans, but it was difficult to ascertain the extent of damage, if any, within the noodles.

Although the impact zones and damage appear to be very different for the two impacted subscale test articles, the ultimate compression loads were very similar, and much lower than for the pristine test articles: 30,900 lbs. for the short-span impact test article CPA-1A, and 31,700 lbs. for the over-noodle impact test article CPA-2A. These ultimate loads were $39 \%$ and $38 \%$ lower, respectively, than the average of the ultimate loads for the comparable pristine test articles discussed previously. For both test articles, the failure was a sudden transverse failure across the entire test article that ran through the impact point. Examination of the axial compressive strains (shown in Fig. 8) shows that there were significantly higher strains and strain gradients in the immediate vicinity of the impacts than in the rest of the article's acreage. This indicates that the impact damage significantly changed the response of the test articles.

\section{B. Full-Scale Test Articles}

\section{Pristine Full-Scale Test Articles}

The finite-element mesh for the pristine full-scale test articles is shown in Fig. 9. The model had 31,636 nodes, 63,258 elements and a total of 187,479 degrees of freedom. As described earlier, one inch at each end was considered potted.

As with the subscale test articles, a geometrically nonlinear analysis was conducted so the articles' behavior could be predicted up to ultimate failure. In this nonlinear analysis, a small geometric imperfection that was based on the first linear eigenmode was used with an imperfection amplitude of $0.005 \mathrm{in}$. The nonlinear analysis predicted that three failure modes would occur up to and including the ultimate load: (a) distributed local web buckling with 4 half waves along the test-article length at loads of 45,000 lbs. in one outer web and 47,000 lbs. in the other outer web, (b) distributed local facesheet buckling with 6 half waves at 66,000 lbs., (c) compression failure of the outermost 0-degree facesheet plies at 74,600 lbs., and (d) compression failure of the outermost 0 -degree flute plies at $75,500 \mathrm{lbs}$. As with the subscale test articles, the local buckling loads were defined as occurring at the first point where the load versus strain curves formed an infinite slope. The local web buckling events were defined based on the load and axial strains at positions centered on the webs and $1.5 \mathrm{in}$. from the lower potting. The local facesheet buckling events were defined based on the load and axial strains in positions centered in each of the three long spans and 1.5 in. from the lower potting. Local buckling values are reported only for those considered positions that had load versus strain curves with infinite-slope points. Fig. 10 shows the predicted facesheet and web buckling shapes at ultimate load. As indicated by the red lines on Fig. 10, the facesheet compression failure was predicted to occur at the peak of the concave local facesheet buckling half-waves.

As summarized in Table 2, the experimental results for the pristine full-scale test articles (designated HL-1B and HL-2B) agreed well with the analytical predictions. The local web-buckling loads in HL-1B and HL-2B were between $48,000 \mathrm{lbs}$. and 51,000 lbs. These loads are within $9 \%$ of the higher predicted web buckling load of 47,000 lbs. As the web buckling pattern developed, there was also good qualitative agreement between the experiments and 


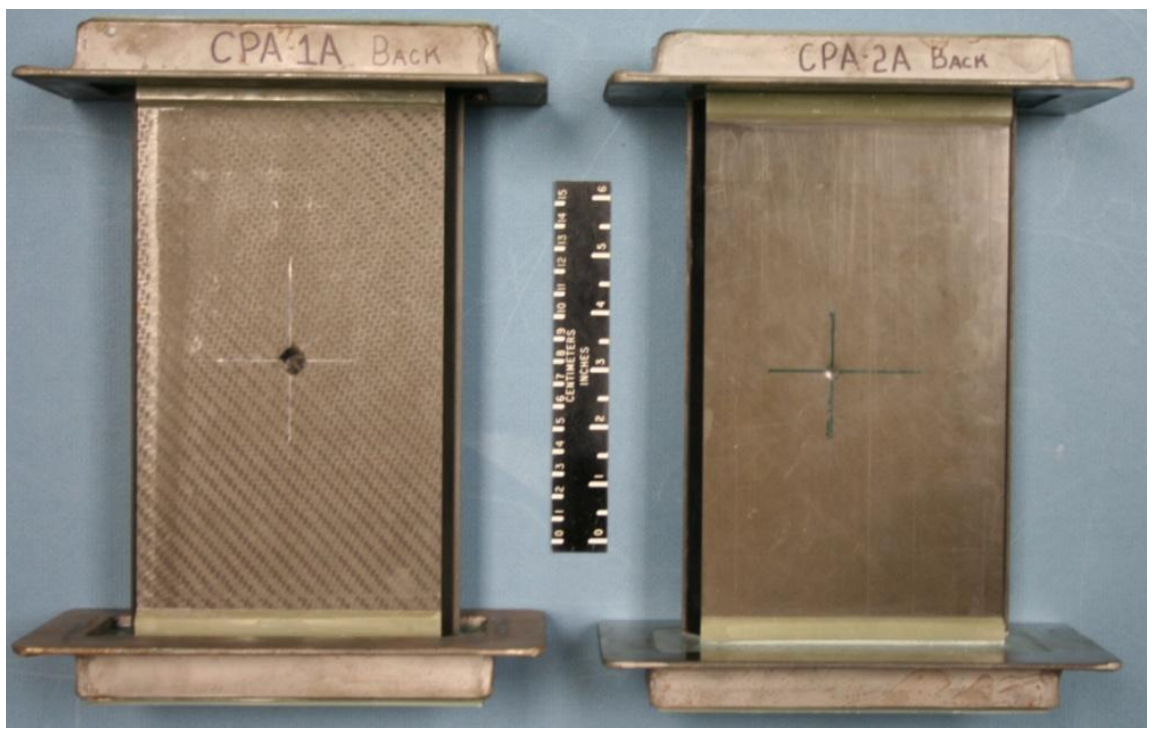

(a) Impacted subscale test articles CPA-1A (left) and CPA-2A (right)

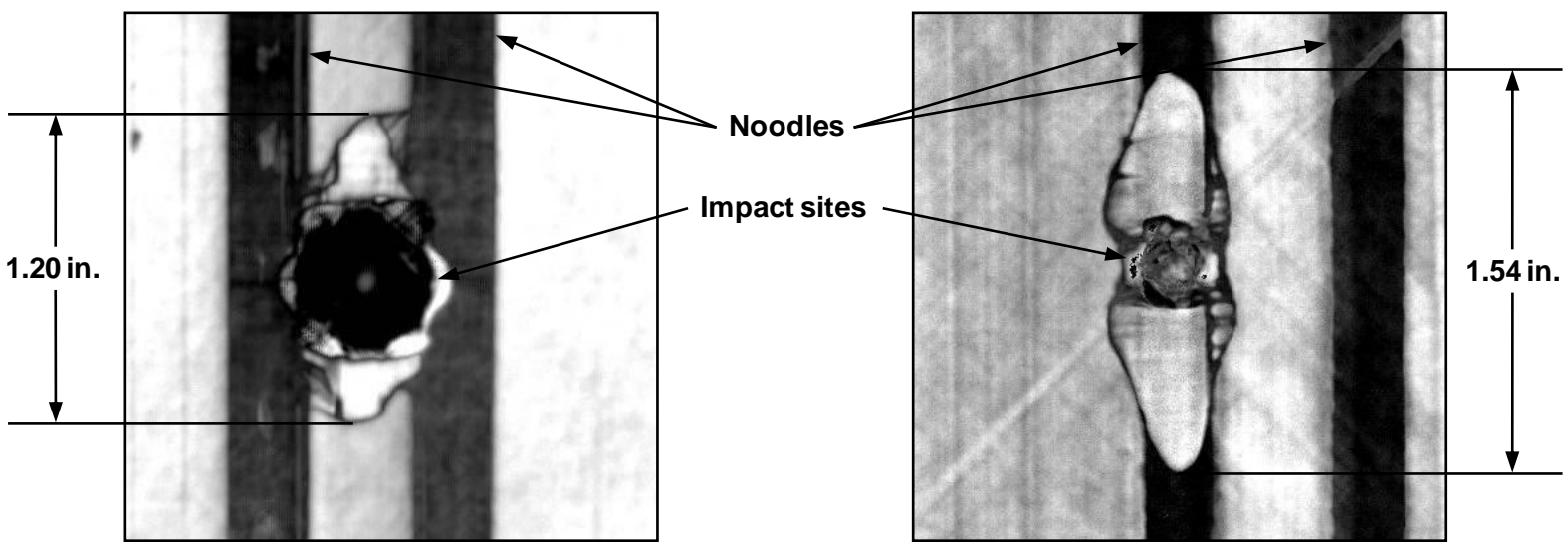

(b) Ultrasonic scan of CPA-1A impacted region

(c) Ultrasonic scan of CPA-2A impacted region

Figure 7. Impacted subscale test articles.

the predictions. For both test articles, the fully developed web buckling mode had 6 or 7 half waves along both external webs. These patterns are shown in Figs. 11a and 11b for test article HL-1B, and compare well to the prediction of 6 half waves in the webs shown in Figs. 10a and 10b. Interestingly, for both test articles the mode shape in the webs transitioned between 6 and 7 half waves as the load increased. The second predicted failure mode, local facesheet buckling, was seen experimentally with measured buckling loads of $66,000 \mathrm{lbs}$. and 73,000 lbs. for test article HL-1B; these buckling loads were within $11 \%$ of the prediction of $66,000 \mathrm{lbs}$. For test article HL-2B, facesheet buckling was measured at 63,000 lbs., 5\% lower than the prediction. The experimental buckling modes were similar to those predicted; however, there was less uniformity in the experimental modes. For example, in the center flute on the back of HL-1B, initially 7 half waves began to develop, but then the mode transitioned to four half waves. Looking at the front of HL-1B, the left flute had three half waves skewed toward the bottom and the buckling in the right flute initially developed 3 half waves, transitioned to 6 half waves, and finally transitioned to 4 half waves by failure. On the back side of HL-2B, 5 half waves developed, and on the front side the two outer flutes both developed 6 half waves. The experimental out-of-plane displacements, just prior to the ultimate load, for the faces of HL-1B are shown in Figs. 11c and 11d. Finally, the ultimate failure loads were 75,600 lbs. for HL-1B and $71,300 \mathrm{lbs}$. for HL-2B, which are about $1 \%$ higher and $4 \%$ lower than the predicted facesheet failure load of 76,600 lbs., respectively. Because the predicted buckling pattern was nearly symmetric, failure was predicted to occur essentially simultaneously in outward facing local buckles on both the front and back. On HL-1B, the failure occurred through an outer half wave on the back and through inner and outer half waves on the front; failure 


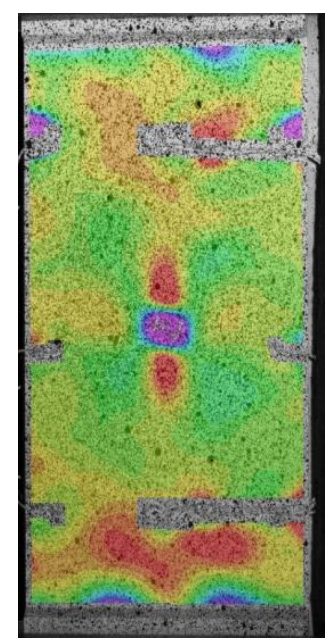

(a) CPA-1A at 30,900 lbs. applied compressive load.

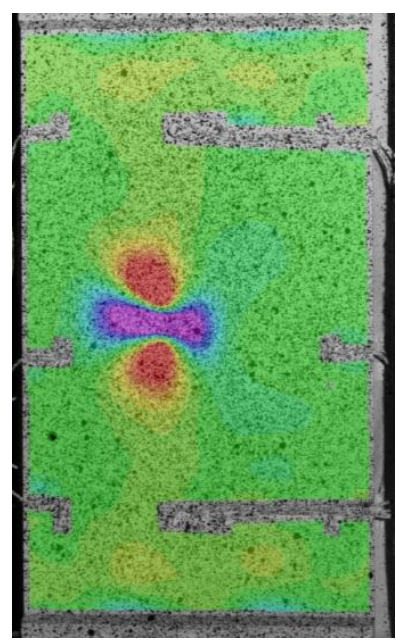

(b) CPA-2A at 31,600 lbs. applied compressive load.

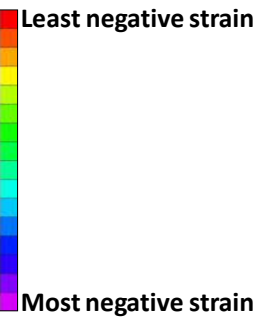

Figure 8. Experimentally observed axial strains for impacted subscale specimens.

locations are shown with the red lines in Fig. 11. However, on HL-2B the failure occurred through one of the outward half waves on the front and through an inward half wave on the back; it was difficult to determine whether the failure began on the front or the back.

\section{Impacted Full-Scale Test Articles}

Two full-scale test articles were also tested after impact with $6 \mathrm{ft}$.-lbs. of energy from a $1 / 2$-in. spherical indenter. Test article HL-1A was impacted in the center of the test article back side, over the long span between noodles, and test article HL-2A was impacted on the test article front side directly over a noodle (Table 2). The large-span impact caused visible damage with a dent depth of $0.005 \mathrm{in}$., and no visible facesheet rupture. This impact is seen in the ultrasonic scan of Fig. 12a; the damage consisted of delaminations at multiple interfaces through the facesheet laminate. The over-noodle impact caused a 0.003 -in. dent depth, and no visible facesheet rupture. In this case the damage zone was contained within the noodle region, and consisted of multiple delaminations through the thickness of the facesheet (Fig. 12b). For impact at both locations, delamination in the facesheets were clear in the ultrasonic scans. However, it was difficult to ascertain the extent of damage, if any, within the noodle in the case of the overnoodle impact.

As summarized in Table 2, both of the impacted full-scale test articles progressed through the failure modes in a manner similar to the pristine test articles. Both local web buckling and local facesheet buckling were observed in the impacted test articles. Local web buckling occurred between 49,000 lbs. and 53,000 lbs., within $13 \%$ of the larger pristine prediction of 47,000 lbs. for the pristine panels. Each of the outer webs of HL-1A and HL-2A had 6 or 7 half waves, with transitions from 7 to 6 half waves in three of the four outer webs of the impacted test articles. The fourth outer web had 7 half waves and did not change mode. Test article HL-1A had a local facesheet buckling load of 66,000 lbs., which was the same as the pristine predicted load. Test article HL-1A developed 5 half waves in the center flute on the back side and 4 half waves in each of the outer flutes of the front side. Test article HL-2A developed 7 half waves in the center flute on the back side and 4 half waves in each of the outer flutes on the front side, but the buckling loads could not be quantified because the considered load vs. strain curves did not have any points of infinite slope. The ultimate failure loads for HL-1A and HL-2A were 68,000 lbs. and 61,600 lbs., respectively. These failure loads were respectively $9 \%$ and $17 \%$ lower than the failure loads predicted for the pristine panels and $7 \%$ and $16 \%$ lower than the average failure load of the pristine experimental test articles. Though these failure loads are lower than those of the pristine test articles, there was no discernable change in the deformed shapes or strain contours due to the impact damage. This is in contrast to the subscale test articles, which showed localized high strains in the vicinity of the impact sites.

\section{Concluding Remarks}

Fluted-core composite structures have the potential to provide benefits over traditional sandwich composites for certain aerospace applications, and recent advances in manufacturing methods have made the use of the fluted-core 


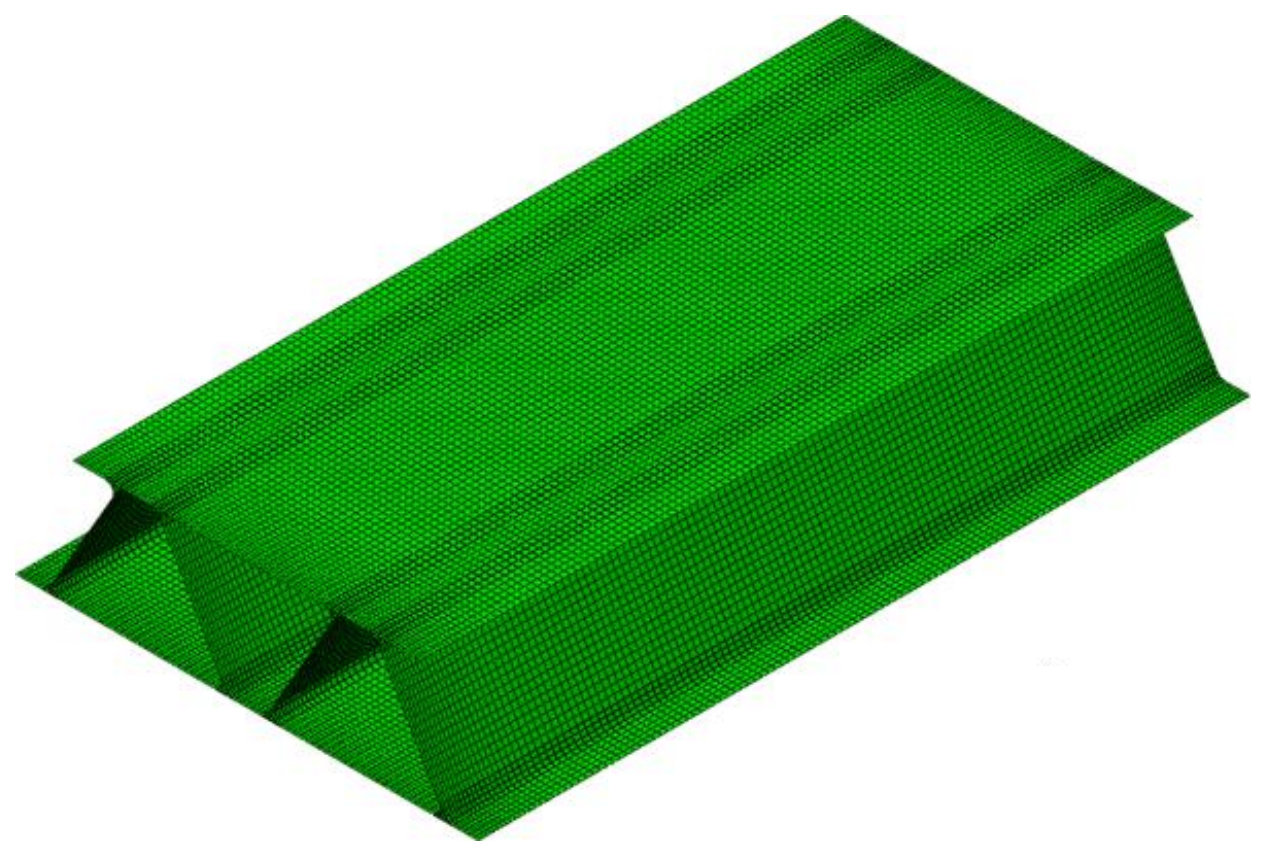

Figure 9. Finite-element mesh for the full-scale test articles.

construction more practical. However, if these structures are to be more widely used, the behavior of fluted-core composites needs to be well understood. Because the primary loading condition in many applications would be compression, the compression behavior of two fluted-core constructions was considered both experimentally and analytically. Both pristine and impact-damaged test articles were tested. Analyses of the pristine test articles were performed and good qualitative and quantitative agreement was obtained between experimentation and analysis. Both buckling and strength failures were observed in the tested components. The stability failures resulted in platelike local buckling patterns that were axially distributed along individual flutes. Depending on the sectional design, these patterns developed in either the facesheets or in the webs. Though these local-buckling events were not catastrophic by themselves, the deformations associated with the local buckling patterns led to material strength failures as loading was increased into the post-buckled range of loading. Considering this, it is important to note that the proper material failures would not be captured by either linear analyses or nonlinear smeared-shell analyses. Nondestructive inspection of the damage zones in impacted test articles showed that the detectable damage region was limited to no more than one flute on either side of the impact. More study is needed, but this may indicate an inherent damage-arresting capability associated with fluted core. This capability could prove beneficial when designing weight-critical damage-tolerant structures for a variety of loading conditions and final products.

\section{References}

${ }^{1}$ McArthur, J. Craig, “Ares I Crew Launch Vehicle, Upper Stage Element Overview,” July 23, 2008, online presentation, URL: http://ntrs.nasa.gov/archive/nasa/casi.ntrs.nasa.gov/20090002561_2008048226.pdf, [cited 23 December, 2010].

${ }^{2}$ Cockrell, Charles E., Jr., "Ares V: Overview and Status," October 12-16, 2009, online presentation, URL: http://ntrs.nasa.gov/archive/nasa/casi.ntrs.nasa.gov/20090043023_2009044061.pdf, [cited 23 December, 2010].

${ }^{3}$ Jegley, Dawn C., "A Study of the Structural Efficiency of Fluted Core Graphite-Epoxy Panels," NASA TM-101681, 1990.

${ }^{4}$ Libove, C., and Hubka, Ralph E., "Elastic Constants for Corrugated-Core Sandwich Plates,” NACA TN $2289,1951$.

${ }^{5}$ Seide, Paul, "The Stability Under Longitudinal Compression of Flat Symmetric Corrugated-Core Sandwich Plates with Simply Supported Loaded Edges and Simply Supported or Clamped Unloaded Edges," NACA TN 2679, 1952.

${ }^{6}$ Lok, Tat-Seng, and Cheng, Qian-Hua, "Elastic Stiffness Properties and Behavior of Truss-Core Sandwich Panel," Journal of Structural Engineering, May 2000, pp. 552-559.

${ }^{7}$ Chang, Wan-Shu, Ventsel, Edward, Krauthammer, Ted, and John, Joby, "Bending Behavior of Corrugated-Core Sandwich Plates," Composite Structures, Vol. 70, 2005, pp. 81-89.

${ }^{8}$ Martinez, Oscar A., Sankar, Bhavani V., Haftka, Raphael T., Bapanapalli, Satish K., and Blosser, Max L., "Micromechanical Analysis of Composite Corrugated-Core Sandwich Panels for Integral Thermal Protection Systems," AIAA Journal, Vol. 45, No. 9, September 2007, pp. 2323-2336. 


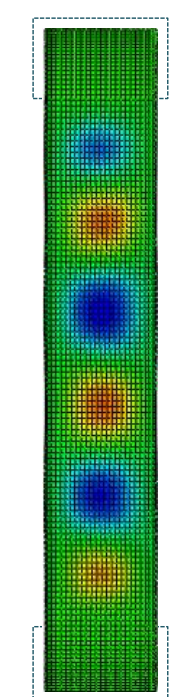

(a) Left web

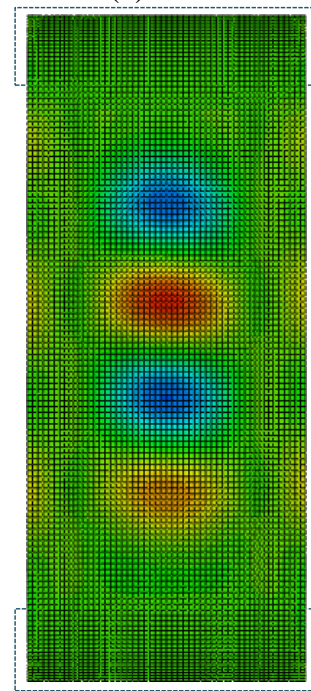

(c) Back facesheet

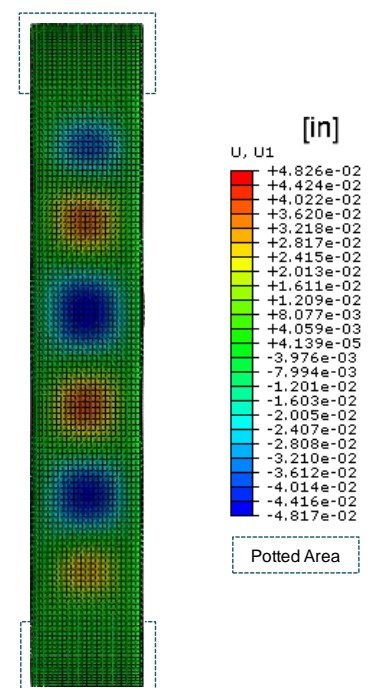

(b) Right web

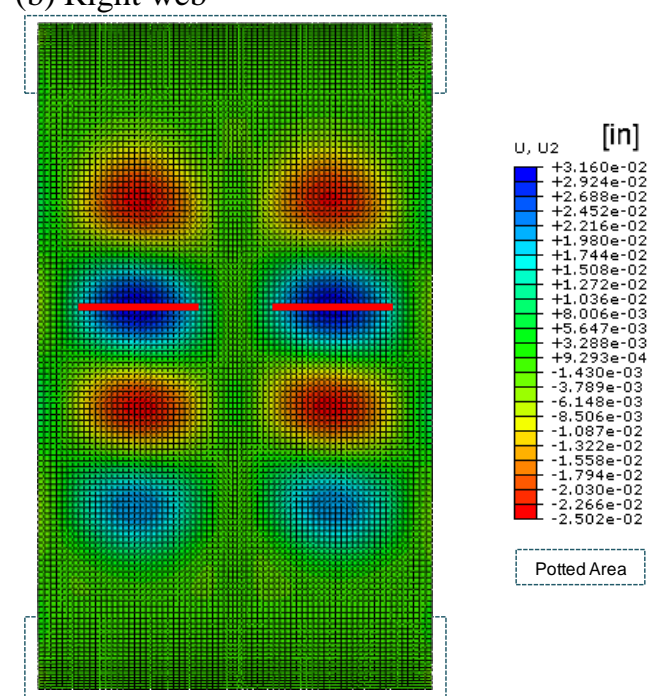

(d) Front facesheet

\section{Figure 10. Predicted out-of-plane displacements for the predicted ultimate load $(\mathbf{7 4 , 6 0 0} \mathrm{lbs}$.$) .$}

${ }^{9}$ Sharma, Anurag, Sankar, Bhavani V., and Haftka, Raphael T., "Homogenization of Plates with Microsctructure and Application to Corrugated Core Sandwich Panels," 51 st AIAA/ASME/ASCE/AHS/ASC Structures, Structural Dynamics, and Materials Conference, Orlando, FL, 12-15 April 2010, AIAA Paper No. AIAA 2010-2706.

${ }^{10}$ Robinson, Michael J., Stoltzfus, Joel M., and Owens, Thomas N., "Composite Material Compatibility with Liquid and Gaseous Oxygen," 42 ${ }^{\text {nd }}$ AIAA/ASME/ASCE/ASC Structures, Structural Dynamics, and Materials Conference and Exhibit, Seattle, WA, 16-19 April 2001, AIAA Paper No. AIAA 2001-1215.

${ }^{11}$ Robinson, Michael J., Johnson, Scott E., Eichinger, Jeffrey D., Hand, Michael L., and Sorensen, Eric T., "Trade Study Results for a Second-Generation Reusable Launch Vehicle Composite Hydrogen Tank," 45 ${ }^{\text {th }}$ AIAA/ASME/ASCE/AHS/ASC Structures, Structural Dynamics \& Materials Conference, 19-22 April 2004, Palm Springs, CA, AIAA Paper No. AIAA 20041932.

${ }^{12}$ Ardelean, Emil, Gerhart, Charlotte, Henderson, Kyle, Griffin, Steve, Lazzaro, Anthony, Evert, Michael, and McCrary, Warren, "Experiment Overview and Flight Results Summary From The Vibro Acoustic Launch Protection Experiment (VALPE)," AIAA Space 2004 Conference and Exhibit, San Diego, CA, 28-30 September 2004, AIAA Paper No. AIAA 20045890.

${ }^{13}$ Kothari, Ajay P., Livingston, John W., Tarpley, Christopher, Raghavan, Venkatraman, Bowcutt, Kevin G., and Smith, Thomas R., "A Reusable, Rocket and Airbreathing Combined Cycle Hypersonic Vehicle Design for Access-to-Space," AIAA Space 2010 Conference and Exposition, 30 August-2 September 2010, AIAA Paper No. AIAA 2010-8905. 
${ }^{14}$ Campbell, F. C., Manufacturing Processes for Advanced Composites, Elsevier, New York, 2004.

${ }^{15}$ Guzman, Juan C., and McCarville, Douglas A., "Comprehensive Overview of Fluted Core for Weight Critical Applications," Airtec Supply on the Wings, Frankfurt, Germany, 2010 (abstract and presentation only).

${ }^{16}$ VIC-3D, Software Package, Ver. 2010.1.0, Correlated Solutions, Inc., Columbia, SC, 2010.

${ }^{17}$ MSC.PATRAN 2010, Software Package, MSC.Software Corporation, Santa Ana, CA, 2010.

${ }^{18}$ Abaqus/Standard, Software Package, Ver. 6.9.1, SIMULIA, Providence, RI, 2009.

${ }^{19}$ Abaqus/CAE, Software Package, Ver. 6.9.1, SIMULIA, Providence, RI, 2009.

${ }^{20}$ Reeder, James R., "Property Values for Preliminary Design of the Ares I Composite Interstage," Memo, 14 March 2007, pg. 7, Table $1,1^{\text {st }}$ column.

Table 2: Analysis and experimental results for pristine and impacted full-scale specimens.

\begin{tabular}{|c|c|c|c|c|c|}
\hline & $\begin{array}{l}\text { Analysis } \\
\text { (pristine) }\end{array}$ & $\begin{array}{l}\text { HL-1B } \\
\text { (pristine) }\end{array}$ & $\begin{array}{l}\text { HL-2B } \\
\text { (pristine) }\end{array}$ & $\begin{array}{c}\text { HL-1A } \\
\text { (impacted) }\end{array}$ & $\begin{array}{c}\text { HL-2A } \\
\text { (impacted) }\end{array}$ \\
\hline Local web buckling loads, lbs. & $\begin{array}{l}45,000 \\
47,000\end{array}$ & $\begin{array}{l}50,500 \\
51,000\end{array}$ & $\begin{array}{l}48,000 \\
49,000\end{array}$ & $\begin{array}{l}50,000 \\
53,000\end{array}$ & $\begin{array}{l}49,000 \\
49,000\end{array}$ \\
\hline $\begin{array}{l}\text { Local facesheet } \\
\text { buckling loads, lbs. }\end{array}$ & 66,000 & $\begin{array}{l}73,000 \\
66,000\end{array}$ & 63,000 & 66,000 & N/A \\
\hline $\begin{array}{l}\text { Final half-wave number } \\
\text { (right, left, back, front) }\end{array}$ & $6,6,4,4$ & $7,6,4,3 \& 4$ & N/A, $6,5,6$ & $7,6,5,4$ & $6,6,7,4$ \\
\hline Ultimate failure load, lbs. & 74,600 & 75,600 & 71,300 & 68,000 & 61,600 \\
\hline Impact location & None & None & None & Long span & Noodle \\
\hline
\end{tabular}

15

American Institute of Aeronautics and Astronautics 


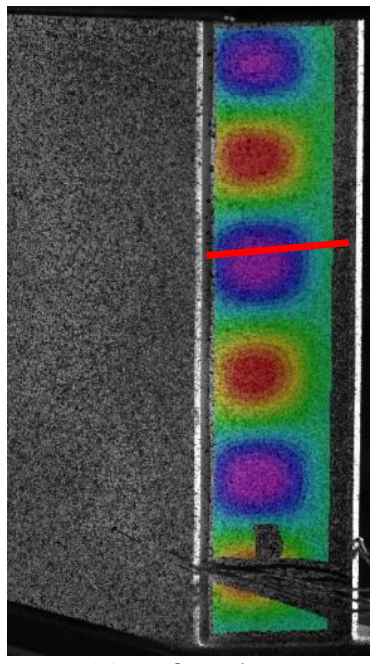

(a) Left web

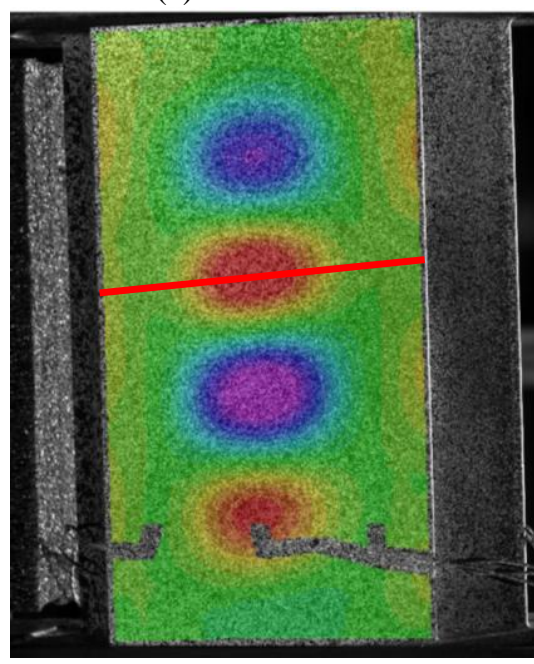

(c) Back facesheet

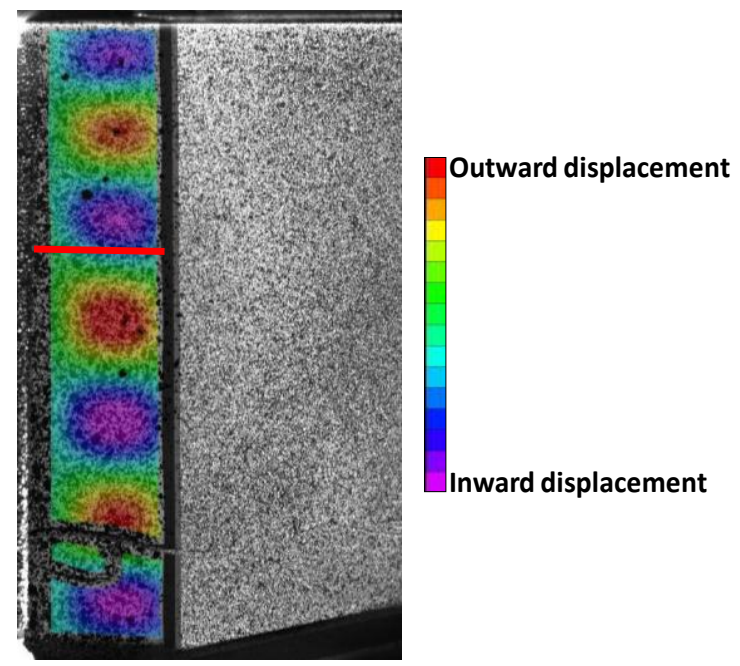

(b) Right web

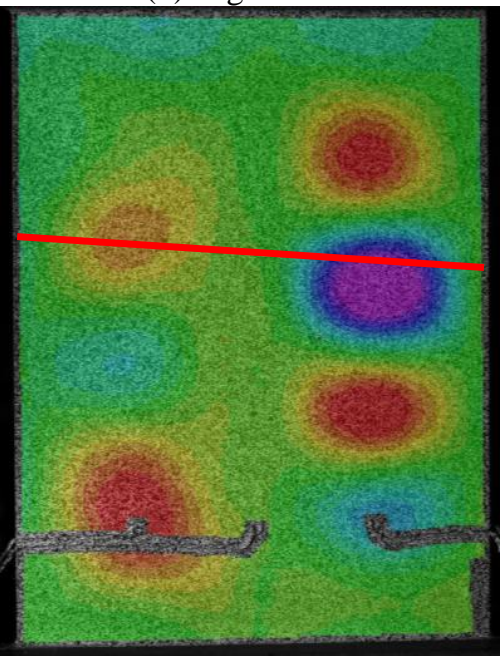

(d) Front facesheet

Figure 11. Experimental out-of-plane displacements for HL-1B just prior to failure $\mathbf{( 7 5 , 6 0 0}$ lbs.). Red lines indicate locations of compression failure.

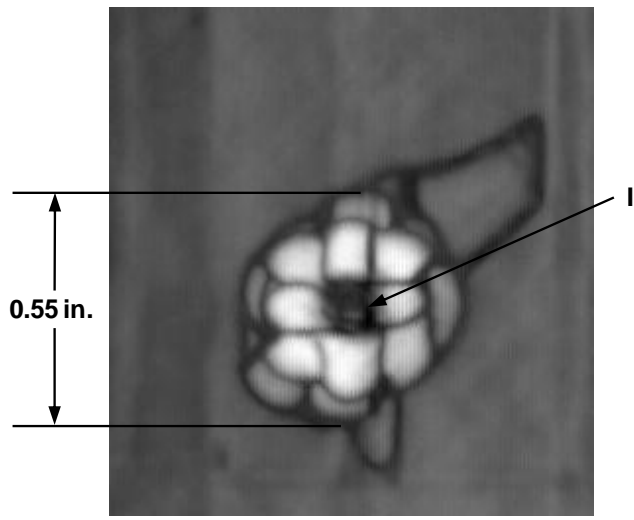

(a) Ultrasonic scan of HL-1A impacted region.

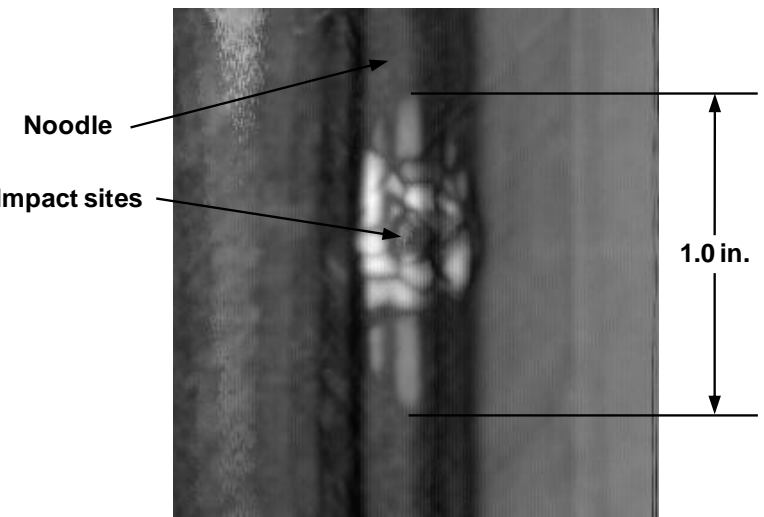

(b) Ultrasonic scan of HL-2A impacted region.

Figure 12. Impacted full-scale test articles. 